\title{
TAHSP:-
}

The Internet Joưnal of Allied Health Sciences and Practice

A Peer Reviewed Publication of the College of Health Care Sciences at Nova Southeastern University

Dedicated to allied health professional practice and education

http://ijahsp.nova.edu Vol. 12 No. 1 ISSN 1540-580X

\section{Systematic Desensitization of Hyperacusis and Vocal Pitch Disorder Treatment in a Patient with Autism}

\author{
Jim Steiger, Ph.D. ${ }^{1}$ \\ Susan U. Ruhlin, M.A. ${ }^{2}$
}

1. Professor, School of Speech-Language Pathology and Audiology, The University of Akron, Akron, Ohio

2. Associate Lecturer, School of Speech-Language Pathology and Audiology, The University of Akron, Akron, Ohio

United States

CITATION: Steiger J, Ruhlin S. Systematic Desensitization of Hyperacusis and Vocal Pitch Disorder Treatment in a Patient with Autism. The Internet Journal of Allied Health Sciences and Practice. Jan 2014. Volume 12 Number 1.

\begin{abstract}
Background: Hyperacusis is the difference in $\mathrm{dB}$ between a normal threshold of audibility for a stimulus and the $\mathrm{dB}$ level at which that stimulus becomes intolerably loud. Some persons with autism exhibit symptoms of hyperacusis possibly attributable to phobias to auditory stimuli. Desensitization procedures have been used as a treatment for phobias and appear a promising treatment for patients with autism and hyperacusis. Methods: Our participant was a 26 year old male previously diagnosed Asperger's syndrome who presented with hyperacusis to low-pitched voices and a concomitant vocal disorder manifesting mainly as high vocal pitch. Despite not fully accepting treatment goals he agreed to treatment in our clinic. A systematic auditory desensitization program was employed to treat hyperacusis, including use of recorded male voices, musical instruments, and environmental sounds. In addition, a modified vocal re-education therapy program was also employed which included instruction on easy onset of phonation, biofeedback, ergonomic progressive imagery relaxation techniques and home exercises to reduce vocal hyperfunction and promote phonatorily efficient breath-stream management. Results: Initial, 7 month, and 13 month hyperacusis measures and voice evaluations were conducted. Hyperacusis evaluations showed our participant's hyperacusis for lower-frequency tones improved by up to $30 \mathrm{~dB}$ bilaterally and his hyperacusis for running speech improved $40 \mathrm{~dB}$ improved in the right ear and $35 \mathrm{~dB}$ in the left ear. His vocal pitch, measured as fundamental vocal frequency, improved from $404.471 \mathrm{~Hz}$ to $280.78 \mathrm{~Hz}$. Conclusions: Our systematic auditory desensitization program decreased our participant's hyperacusis and our modified vocal re-education therapy (VRT) program lowered his vocal pitch. However, the results did not generalize beyond the clinic. The latter may be attributable to our participant's unwillingness to fully accept treatment goals, which may serve as a caveat to future clinicians to consider prognosis prior to making treatment decisions.
\end{abstract}

\section{INTRODUCTION}

Hyperacusis

Hyperacusis involves reduced dynamic range, that is, the difference in $\mathrm{dB}$ between a normal threshold of audibility for a stimulus and the $\mathrm{dB}$ level at which that stimulus becomes intolerably loud.1,2 Hyperacusis appears to be rare; for example, Vernon and Meikle estimated 32,000 Americans suffer from tinnitus and hyperacusis. ${ }^{3}$ Hyperacusis also frequently occurs with more bothersome tinnitus. Fifty three percent of tinnitus and hyperacusis suffers reported hyperacusis to be the more bothersome symptom, while $19 \%$ judged their tinnitus and hyperacusis to be equally bothersome. ${ }^{3}$ Bothersome hyperacusis can manifest as intolerance for many common sounds, especially sudden sounds. Hyperacusis sufferers sometimes compensate by sound avoidance and use of sound attenuating earplugs. ${ }^{2,3}$

The physiologic correlates of hyperacusis remain elusive. Jastreboff proposed that the typical genesis of hyperacusis is peripheral auditory damage, specifically to the cochlear outer hair cells. ${ }^{4}$ This results in a compensatory increase in associated 
neuronal sensitivity and activity in the central auditory system, and bothersome hyperacusis was hypothesized to result from resulting involvement of the limbic and autonomic nervous systems. Evidence for such increased neuronal activity and limbic system activation has been reported, and several cellular mechanisms at the synaptic and neural transmitter level have been proposed. $5-10$

There is a lack of agreement regarding what precisely constitutes reduced dynamic range in $\mathrm{dB} .^{3}$ Not surprisingly then, it is unclear from objective data who will need treatment and who will not. Most patients with hyperacusis do not require treatment for their hyperacusis, and the need for treatment can be determined by case history. ${ }^{11}$ Recommended treatment includes gradually increasing levels of ambient noise over time, with emphasis on enjoyable sounds through both passive and active listening opportunities. ${ }^{11}$ These authors report that this treatment, along with education, often results in resolution of hyperacusis within a year. Vernon and Press similarly recommended desensitization using noise stimuli, and they reported hyperacusis resolution to range from 3 months to 2 years. ${ }^{2}$

\section{Hyperacusis and Autism}

Some persons with autism exhibit symptoms of hyperacusis. ${ }^{12-15}$ However, hyperacusis in this population might have little to do with the peripheral or central auditory systems of sufferers. Gomes, Rotta, Pedroso, Sleifer and Danesi provided evidence that hyperacusis in autism patients is more likely due to "...difficulties in the upper processing at the level of the cerebral cortex, involving systems that usually are impaired in autistic spectrum patients, such as the limbic system." ${ }^{2}$ Similarly, Stiegler reported there is essentially no evidence of physiological manifestations in the auditory systems of children with autism who exhibit hyperacusis. ${ }^{15}$ Said differently, the genesis and progression of hyperacusis proposed by Jastreboff does not explain hyperacusis among persons with autism. ${ }^{4}$ In lieu of auditory dysfunction, authors have suggested that phobias to auditory stimuli may explain the hyperacusis and related symptoms of fear and anxiety among those with autism. ${ }^{15,16}$

There has been a lack of clarity on how to treat hyperacusis in persons with autism perhaps owing to our evolving understanding of etiology. ${ }^{17}$ However, desensitization, which has been used as a treatment for phobias, appears a promising option for patients with autism and hyperacusis. For example, Koegel, Openden, and Koegel reported positive outcomes in children with autism using an approach that included a gradual and systematic closing of physical proximity to the objects that emitted aversive sounds. ${ }^{13}$ Similarly, Stiegler used systematic auditory desensitization augmented with specially constructed stories with pictures to help children understand and cope with noises in various situations. ${ }^{15}$ Morris used computer technology to introduce pictures and sounds in a systematic auditory desensitization process to treat adults with autism and hyperacusis. ${ }^{18}$

Though desensitization procedures have been used to treat adults with autism and hyperacusis, such treatment being used on a patient with associated voice disorder has not been found in the research literature. The purpose of this paper is to describe the case of a 26-year-old male previously diagnosed with an autism spectrum disorder who presented to a university speechlanguage pathology and audiology clinic with hyperacusis and a concomitant vocal pitch disorder. More specifically, we present our efforts to treat the patient using desensitization for hyperacusis and re-education voice therapy for his voice disorder.

\section{METHODS \\ Participant}

$\mathrm{HP}$, a 26 year old male, served as the participant in this case study. He was a college senior with previously diagnosed Asperger's syndrome, Tourette's syndrome, obsessive/compulsive disorder, social anxiety disorder, hyperacusis, spasmodic dysphonia, and a concomitant vocal pitch disorder. The onset of the hyperacusis and vocal pitch disorder was reportedly simultaneous, occurring around puberty when his voice naturally began lowering in pitch. His dislike of his changing vocal pitch resulted in a gradual increase of his vocal pitch to its current falsetto pitch marked by severe vocal hyperfunction. HP described low-pitched voices, especially male but also female, as uncomfortable, having the effect "like fingers scraping a chalkboard." HP verbalized comprehension that his current vocal profile was incompatible with normal male laryngeal size, structure, and function. He reported he had been under the care of a mental health counselor for five years, which included treatment for his social anxiety disorder and explorations of possible explanations for his preferred vocal pitch.

HP's commitment to evaluation and potential treatment was questionable; he repeatedly indicated that he believed his highpitched voice was an effective treatment for his hyperacusis to his own low-pitched voice, and that he was content to avoid people to minimize exposure to other low pitched voices. He was similarly unconcerned about the apparent vocal tension, even when potential laryngeal damage was discussed. Nonetheless, he agreed to therapy partly at the urging of his parents.

\section{Voice Treatment}

A modified vocal re-education therapy (VRT) program was designed to promote muscular relaxation, easy onset of phonation, 
and to lower HP's vocal pitch.19 Therapy was augmented by biofeedback and ergonomic progressive imagery relaxation techniques to reduce vocal hyperfunction and promote phonatorily efficient breath-stream management. Independent home exercise programs were also provided to reinforce learned skills in relaxation and respiratory management. In accordance with noted obsessive-compulsive behavior, these activities were consistently completed in great length and detail by HP. In addition, client and parental counseling was included in weekly visits.

\section{Systematic Auditory Desensitization}

The systematic auditory desensitization program for hyperacusis that was carried out at home was also supported by his mental health counselor. Compulsive adherence was reported by HP, who kept a detailed daily log throughout the duration of treatment. During the first approximately 6 month period, the subject listened to enjoyable instrumental music for 30 to 60 minutes a day through his home stereo which had controls for base (lower frequencies) and treble (higher frequencies). Initially, HP was asked to turn the base to a just audible level, then to increase the base intensity progressively over the subsequent weeks and months until treble and base were subjectively balanced in intensity. However, HP reported a strong aversion to the notes from the lowpitched instruments. He reported pessimism regarding prognosis and requested a change of stimuli. He indicated he had an interest in weather and particularly liked thunderstorms. During the second approximately 6 month period of treatment, HP listened to a thunderstorm CD for 30 to 60 minutes a day. Again, initially HP was asked to turn the base to a just audible level, then increase base intensity progressively over the subsequent weeks and months until treble and base were subjectively balanced in intensity. Finally, he progressed to systematic auditory desensitization using a male voice as stimuli during the final approximately 6 month period. Options discussed included books on tape, talk radio, and music, and it was agreed to use CDs of a singer whose voice and vocal pitch were particularly bothersome. Using two stereos, the music CDs were paired with the subjectively enjoyable thunderstorm $C D$ in the background. The base notes of voice were gradually increased in intensity over several months until treble and base were subjectively balance in intensity.

\section{RESULTS \\ Voice Evaluation}

During the initial evaluation, HP presented with a variable vocal profile marked by severe dysphonia, a high-pitched, strained production, a raspy, airy vocal quality, and poor breath-stream management. In order to speak with this high-pitched voice, considerable vocal tension and effort was necessary, along with other behaviors including respiratory tension, head, neck and torso tension, shoulder elevation, laryngeal elevation, eye blinks, and facial tics. Discussion and observation also revealed the existence of multiple secondary reinforcements for the maintenance of dysfunctional communication behaviors. These reinforcements included family control and manipulation, reduced assumption of adult responsibility, and excuse from social or academic speaking requirements.

The initial objective evaluation included an analysis of running speech using Kay Elemetrics Visipitch Model 5105 and software located on the first author's laptop computer. Consistent with our subjective evaluation, his arithmetic mean fundamental frequency (fo) of $404.471 \mathrm{~Hz}$ and his harmonic mean $\mathrm{f}_{0}$ of $360.379 \mathrm{~Hz}$ exceeded manufacturer reported norms for adult males by several standard deviations (Table 1; the norms were obtained 54 males, mean age 36 years). Measures of jitter, shimmer, relative average perturbations, voice to harmonic ratio, and voice turbulence index also exceeded norms which provided objective evidence of his raspy, airy, and variable voice quality (Table 1).

Table 1. Initial Voice Evaluation Data

\begin{tabular}{|l|l|l|l|}
\hline Parameter & Value & Mean (Norm) & Standard deviation + (Norm) \\
\hline $\begin{array}{l}\text { Fundamental frequency } \\
\text { arithmetic mean }\end{array}$ & $404.471 \mathrm{~Hz}$ & $145.223 \mathrm{~Hz}$ & $23.406 \mathrm{~Hz}$ \\
\hline $\begin{array}{l}\text { Fundamental frequency } \\
\text { harmonic mean }\end{array}$ & $360.379 \mathrm{~Hz}$ & $141.743 \mathrm{~Hz}$ & $21.136 \mathrm{~Hz}$ \\
\hline Highest fundamental frequency & $658.553 \mathrm{~Hz}$ & $150.08 \mathrm{~Hz}$ & $24.362 \mathrm{~Hz}$ \\
\hline Absolute Jitter & $162.761 \mathrm{usec}$ & $41.663 \mathrm{usec}$ & $36.481 \mathrm{usec}$ \\
\hline Relative average perturbation & $3.461 \%$ & $0.345 \%$ & $0.333 \%$ \\
\hline Shimmer \% & $15.497 \%$ & $2.523 \%$ & $0.997 \%$ \\
\hline Shimmer dB & $1.505 \mathrm{~dB}$ & $0.219 \mathrm{~dB}$ & $0.085 \mathrm{~dB}$ \\
\hline Noise to harmonic ratio & 0.449 & 0.112 & 0.14 \\
\hline Voice turbulence index & 0.067 & 0.052 & 0.016 \\
\hline
\end{tabular}


HP's voice was re-evaluated to monitor approximately 7 months post initial evaluation and again near discharge approximately 13 months post initial evaluation using a Kay Elemetrics Visipitch Model 4300B housed in the second author's clinic therapy room. This is a device used for clinic measure that does not assess all of the voice parameters as the model used at the initial evaluation. As show in Table 2, HP's fundamental frequency improved from $404.471 \mathrm{~Hz}$ (initial evaluation) to $280.78 \mathrm{~Hz}$ (final evaluation). Though that amount of improvement is remarkable, his final fundamental frequency remained higher than acceptable for his age and gender.

Table 2. Comparison of Voice Evaluation Data at Initial, Mid-Treatment, and Final Evaluations (DNT = Did Not Test)

\begin{tabular}{|l|l|l|l|}
\hline Parameter & Initial & Initial + 7 months & Initial + 13 months \\
\hline $\begin{array}{l}\text { Fundamental } \\
\text { frequency arithmetic mean }\end{array}$ & $404.471 \mathrm{~Hz}$ & $407.11 \mathrm{~Hz}$ & $\begin{array}{l}280.78 \mathrm{~Hz} \\
\text { Mean (Norm) } 145.223 \mathrm{~Hz} \\
\text { SD (Norm) 23.406 }\end{array}$ \\
\hline $\begin{array}{l}\text { Fundamental frequency } \\
\text { harmonic mean }\end{array}$ & $360.379 \mathrm{~Hz}$ & DNT & DNT \\
\hline $\begin{array}{l}\text { Highest fundamental } \\
\text { frequency }\end{array}$ & $658.553 \mathrm{~Hz}$ & $908.38 \mathrm{~Hz}$ & $\begin{array}{l}649.35 \mathrm{~Hz} \\
\text { Mean (Norm) } 150.08 \mathrm{~Hz} \\
\text { SD (Norm) } 24.362\end{array}$ \\
\hline Absolute jitter & 162.761 usec & DNT & DNT \\
\hline Jitter \% & $5.866 \%$ & DNT & DNT \\
\hline Relative average perturbation & $3.461 \%$ & $3.89 \%$ & $3.01 \%$ \\
& & & $\begin{array}{l}\text { Mean (Norm) } 0.345 \% \\
\text { SD (Norm) } 0.333 \%\end{array}$ \\
\hline Shimmer \% & $15.497 \%$ & DNT & DNT \\
\hline Shimmer dB & $1.505 \mathrm{~dB}$ & DNT & DNT \\
\hline Noise to harmonic ratio & 0.449 & DNT & DNT \\
\hline Voice turbulence index & 0.067 & DNT & DNT \\
\hline
\end{tabular}

\section{Audiometrics}

An audiologic evaluation was conducted in an audiometric sound booth using a Grason Stadler 61 audiometer routed to EAR insert earphones. The results included normal hearing sensitivity bilaterally as evidenced by pure tone thresholds $\leq 15 \mathrm{~dB} H \mathrm{HL}$ from $250 \mathrm{~Hz}$ through $8000 \mathrm{~Hz}$. Distortion product otoacoustic emissions were normal bilaterally, consistent with normally functioning outer hair cells. His loudness discomfort levels (LDLs) were measured in $5 \mathrm{~dB}$ steps using the protocol recommended by Henry and Zaugg. ${ }^{20}$ The stimuli were pure tones presented at octave frequencies from $250 \mathrm{~Hz}$ through $8000 \mathrm{~Hz}$ and male talker running speech (the first author, whose arithmetic mean $f_{0}$ was $129.8 \mathrm{~Hz}$ as measured with the Kay Visipitch Model 5105 voice analyzer). HP's LDLs were normal $(100+d B)$ for tones from $2000 \mathrm{~Hz}$ through $8000 \mathrm{~Hz}$. However, as shown in Table 3, his initial LDLs were only $20 \mathrm{~dB}$ to $80 \mathrm{~dB}$ for lower-frequency tones from $125 \mathrm{~Hz}$ to $500 \mathrm{~Hz}$ in the right ear, and $20 \mathrm{~dB}$ to $60 \mathrm{~dB}$ for lower-frequency tones from $125 \mathrm{~Hz}$ to $1000 \mathrm{~Hz}$ in his left ear. His LDLs for running speech were $25 \mathrm{~dB}$ for the right ear and $30 \mathrm{~dB}$ for the left ear. These findings were generally consistent with HP's complaint of hyperacusis to low-pitch voices.

Table 3. Loudness Discomfort Levels for Tones and Male Running Speech at Initial Evaluation, Mid-treatment Evaluation, and Final Evaluations

\begin{tabular}{|l|l|l|l|l|l|l|}
\hline & $\begin{array}{l}\text { Initial } \\
\text { evaluation }\end{array}$ & & $\begin{array}{l}\text { Initial + 7 } \\
\text { months }\end{array}$ & & $\begin{array}{l}\text { Initial + 13 } \\
\text { months }\end{array}$ & \\
\hline & Right ear & Left ear & Right ear & Left ear & Right ear & Left ear \\
\hline $125 \mathrm{~Hz}$ & $20 \mathrm{~dB}$ & $20 \mathrm{~dB}$ & $30 \mathrm{~dB}$ & $45 \mathrm{~dB}$ & $40 \mathrm{~dB}$ & $50 \mathrm{~dB}$ \\
\hline $250 \mathrm{~Hz}$ & $70 \mathrm{~dB}$ & $25 \mathrm{~dB}$ & $35 \mathrm{~dB}$ & $45 \mathrm{~dB}$ & $45 \mathrm{~dB}$ & $55 \mathrm{~dB}$ \\
\hline $500 \mathrm{~Hz}$ & $80 \mathrm{~dB}$ & $55 \mathrm{~dB}$ & $55 \mathrm{~dB}$ & $65 \mathrm{~dB}$ & $65 \mathrm{~dB}$ & $65 \mathrm{~dB}$ \\
\hline $1000 \mathrm{~Hz}$ & $105 \mathrm{~dB}$ & $60 \mathrm{~dB}$ & $75 \mathrm{~dB}$ & $95 \mathrm{~dB}$ & $75 \mathrm{~dB}$ & $90 \mathrm{~dB}$ \\
\hline Speech & $25 \mathrm{~dB}$ & $30 \mathrm{~dB}$ & $50 \mathrm{~dB}$ & $55 \mathrm{~dB}$ & $65 \mathrm{~dB}$ & $65 \mathrm{~dB}$ \\
\hline
\end{tabular}

LDLs were re-measured approximately 7 months post initial evaluation and near discharge approximately 13 months post initial evaluation. Data in Table 3 shows final speech LDLs of $65 \mathrm{~dB}$, a $40 \mathrm{~dB}$ improvement in the right ear and a $35 \mathrm{~dB}$ improvement in the left ear. Similarly, improvement in left ear pure-tone LDLs of up to $30 \mathrm{~dB}$ were measured from $125 \mathrm{~Hz}$ to $1000 \mathrm{~Hz}$. However, LDLs in the right ear improved $20 \mathrm{~dB} 125 \mathrm{~Hz}$ whereas LDLs from 250 to $1000 \mathrm{~Hz}$ worsened up to $30 \mathrm{~dB}$. It is unclear why this worsening took place and whether it might explain HP's report of persistent hyperacusis to low-pitched voices. 


\section{DISCUSSION}

HP's hyperacusis to low-pitched voices reportedly caused him to limit verbal communication and supported his preference for speaking in a high-pitched voice. He had no peripheral audiologic pathology that might lead to hyperacusis as described by Jastreboff. ${ }^{4}$ This suggests his hyperacusis to be a phobia as described in the literature, which might also play a role to related symptoms of fear and anxiety. 13,15,16 Interestingly, his hyperacusis to low-pitched voices began at puberty when his own voice began to change. However, HP also demonstrated hyperacusis to low pitched tones and musical notes. This unexpected finding suggests that either his phobia is for low-pitch in general, or there is also an unexplained physiological disorder in the auditory system manifesting as hyperacusis to low-pitched tones and musical notes.

The initial successes with this patient should encourage future clinicians. HP was able to lower the pitch of his own voice (through voice re-education therapy, relaxation techniques, and breath-stream management), and become more comfortable with his own and at least some other voices (with systematic auditory desensitization). Moreover, noted were reductions of facial tics, head, neck, and torso tension, and eye blinks during structured communication activities. In summary, there is some evidence that two related yet distinct symptoms can be simultaneously treated with positive outcomes in the clinic setting.

However, clinical observation and parental reports suggested HP's vocal pitch improvements were transient and did not generalize beyond the therapy room or voice measurement lab. Similarly, HP continued to report hyperacusis to low-pitched voices despite measured LDL improvements. It appears that improved acceptance of particular voices and musical notes did not ensure improved acceptance of voices in general. It was suspected that HP's reluctance to accept the established therapeutic goals and outcomes of therapy affected his prognosis and outcomes; this is an area that requires further research and clinical consideration. Furthermore, researchers and clinicians should consider whether more coordinated interdisciplinary voice therapy, auditory desensitization, and psychological interventions might lead to greater generalization than that seen for HP.

\section{CONCLUSION}

Desensitization and re-education voice therapy were used to treat a patient with autism, hyperacusis, and associated vocal disorder. The efforts proved successful in the clinic, but did not generalize. The latter is attributed to the patient's lack of desire; this may serve as a caveat to future clinicians to consider prognosis prior to making treatment decisions.

\section{REFERENCES}

1. Aran JM, Dauman R, editors. Hyperacusis and tinnitus. Proceedings of the Fourth International Tinnitus Seminar; 1992 New York: Kugler Publications, 1992.

2. Vernon JA, Press L. Treatment for hyperacusis. In: Vernon JA, editor. Tinnitus treatment and relief. Boston: Allyn \& Bacon; 1998. p. 223-227.

3. Vernon JA, Meikle MB. Tinnitus masking. In: Tyler RS, editor. Tinnitus handbook. San Diego: Singular; 2000. p. $313-56$.

4. Jastreboff PJ. Tinnitus habituation therapy (THT) and Tinnitus Retraining therapy (TRT). In: Tyler RS, editor. Tinnitus handbook. San Diego: Singular; 2000. p. 357-76.

5. Kaltenbach JA. Hyperactivity in the dorsal cochlear nucleus after intense sound exposure and its resemblance to toneevoked activity: a physiological model for tinnitus. Hearing Research. 2000;140(1-2);165-72. [PMID: 10675644]

6. Lockwood AH, Salvi RJ, Coad ML, Towsley ML, Wack DS, Murphy BW. The functional neuroanatomy of tinnitus: Evidence for limbic system links and neural plasticity. Neurology. 1998;50(1):114-20.[PMID:9443467]

7. Bilak M, Kim J, Potashner SJ, Bohne BA, Morest DK. New growth of axons in the cochlear nucleus of adult chinchillas after acoustic trauma. Experimental Neurology. 1997;147(22):256-68.[PMID:9344551]

8. Caspary DM, Ling L, Turner JG, Hughes LF. Inhibitory neurotransmission, plasticity and aging in the mammalian central auditory system. Journal of Experimental Biology. 2008;211:1781-91. [PMID:18490394]

9. Kaltenbach JA, Zhang J. Intense sound-induced plasticity in the dorsal cochlear nucleus of rats: Evidence for cholinergic receptor upregulation. Hearing Research. 2007;226(1-2):232-43.[PMID:16914276]

10. Suneja, SK, Potashner SJ, Benson CG. Plastic Changes in glycine and GABA release and uptake in adult brain stem auditory nuclei after unilateral middle ear ossicle removal and cochlear ablation. Experimental Neurology. 1998;151(2):27388.[PMID:9628763]

11. Henry JA. Zaugg TL, Myers PJ, Schechter MA. The role of audiologic evaluation in progressive audiologic tinnitus management. Trends in Amplification. 2008;12(3):170-87.[PMID:18628281]

12. Gomes E, Rotta NT, Pedroso SF, Sleifer P. Danesi MC. Auditory hyperacusis in children and teenagers with autistic spectrum disorder. Arquivos de Neuro-Psiquiatria. 2004; 62(3-B):797-801.

13. Koegel RL, Openden D, Koegel LK. A systematic desensitization paradigm to treat hyperacusis to auditory stimuli in children with autism in family contexts. Research and Practice for Persons with Severe Disabilities. 2004;29:122-34. 
14. Rimland B, Edelson SM. Brief report: A pilot study of auditory integration training in autism. Journal of Autism and Developmental Disorders. 1995;25(1):61-70.[PMID:7608035]

15. Stiegler L. Understanding sound sensitivity in individuals with autism spectrum disorders. Focus on Autism and Other Developmental Disabilities. 2010;25;67-75. doi:1088357610364530

16. Hemsley R, Howlin P, Berger M, et al. Treating autistic children in a family context. In: Rutter M, Schopler E, editors. Autism: A reappraisal of concepts and treatment. New York: Plenum Press; 1978. p. 379-412.

17. Dawson G, Watling R. Interventions to facilitate auditory, visual, and motor integration in autism: a review of the evidence. Journal of Autism and Developmental Disorders. 2000;30(5):415-21. [PMID:11098877]

18. Morris R. Managing Sound Sensitivity in Autism Spectrum Disorder: New Technologies for Customized Intervention [B.A. thesis]. Massachusetts Institute of Technology; 2003.

19. Mueller PB. Vocal re-education therapy: A Clinician's Guide to the Hyperkinetic Voice. Eau Claire, WI: Thinking publications; 1989.

20. Henry JA, Zaugg TL. Clinical guide for audiologic tinnitus management I: Assessment. American Journal of Audiology. 2005;14:21-48. [PMID:16180968] 